\title{
Drug-induced gynecomastia: A systematic review and meta-analysis of randomized clinical trials
}

\author{
Alberto Trinchieri ${ }^{1}$, Gianpaolo Perletti ${ }^{2,3}$, Vittorio Magri ${ }^{4}$, Konstantinos Stamatiou ${ }^{5}$, \\ Margherita Trinchieri ${ }^{6}$, Emanuele Montanari ${ }^{7}$ \\ ${ }^{1}$ School of Urology, University of Milan, Milan, Italy; \\ ${ }^{2}$ Department of Biotechnology and Life Sciences, Section of Medical and Surgical Sciences, University of Insubria, Varese, Italy; \\ ${ }^{3}$ Faculty of Medicine and Medical Sciences, Ghent University, Belgium; \\ ${ }^{4}$ Urology Secondary Care Clinic, ASST-Nord, Milan, Italy; \\ ${ }^{5}$ Department of Urology, Tzaneio Hospital, Pireus, Greece; \\ ${ }^{6}$ Department of Neuroscience, Psychiatric Unit, University of Parma, Parma, Italy; \\ ${ }^{7}$ Department of Urology, IRCCS Ca' Granda Ospedale Maggiore Policlinico - University of Milan, Milan, Italy.
}

\begin{abstract}
Summary Objective: To review the evidence concerning treatment-related gynecomastia in patients taking spironolactone, antiandrogens, 5 alpha-reductase inhibitors, lipid-lowering and psychotropic drugs.

Material and methods: A search of Medline and EMBASE was performed up to 30 June 2021. We included randomized controlled trials comparing the effects of a drug belonging to these classes versus placebo or versus a drug of the same class. Results: A total of 32 randomized controlled trials were included in the final review. There was an increased odds of gynecomastia in men receiving antiandrogens (OR $=17.38,95 \% \mathrm{CI}: 11.26$ to 26.82; 6 trials, 9599 participants) and 5 alpha-reductase inhibitors compared to controls (OR $=1.77,95 \%$ CI: 1.53 to 2.06; 7 series out of 6 trials, 34860 participants). The use of spironolactone in mixed gender populations was characterized by significantly higher odds of having gynecomastia compared to controls $(\mathrm{OR}=8.39,95 \%$ CI: 5.03 to $13.99 ; 14$ trials, 3745 participants). No placebo-controlled trials focusing on the risk of gynecomastia in patients taking antipsychotic drugs was available, although there was a significant difference in the odds of having gynecomastia in a comparison between risperidone and quetiapine (OR $=4.32$, 95\% CI: 1.31 to 14.27 ; 3 trials, 343 participants). Limited evidence about the effects of statins on mammary glands was found.

Conclusions: Antiandrogens and to a lesser extent 5 alphareductase inhibitors and spironolactone are associated with an increased risk of developing gynecomastia. Such effect can be explained by a modification of the testosterone to estradiol ratio. Gynecomastia (and galactorrhea) associated to the use of conventional and certain atypical antipsychotics can be related to high prolactin levels.
\end{abstract}

KEY WORDS: Gynecomastia; Breast enlargement; Spironolactone; Antiandrogens; 5 alpha-reductase inhibitors; Psychotropic drugs; Statins.

Submitted 20 September 2021; Accepted 1 November 2021

\section{INTRODUCTION}

Gynecomastia is a condition in which the male breast is enlarged due to an increase in ductal tissue, stroma, or fat. Histological observation shows a proliferation of the mammary ducts embedded in a fibroconnective tissue stroma. Gynecomastia is associated with medical conditions such as extreme obesity, hypogonadism, liver, and kidney failure. In addition, the administration of certain drugs is a known risk factor for gynecomastia. According to Food and Drug Administration (FDA) Adverse Event Reporting System, gynecomastia is most frequently reported after administration of inhibitors of 5alpha-reductase (dutasteride, finasteride), spironolactone, antipsychotics, lipid-lowering agents (rosuvastatin, atorvastatin, and simvastatin) and antiandrogens (1).

Other drugs causing gynecomastia include antiretrovirals (protease inhibitors and nucleoside reverse transcriptase inhibitors), histamine2-receptor blockers (cimetidine), antimycotics (long-term use of ketoconazole), calcium channel blockers, and chemotherapeutic agents.

Gynecomastia was also reported after intake of exogenous hormones (estrogens) or steroids (in adolescent boys), and after environmental exposure to phenothrin or intake of phytoestrogens (e.g., large quantities of phytoestrogencontaining soy products).

There are numerous reports on the association between the intake of certain drugs and gynecomastia, but no meta-analysis has so far assessed the extent of the risk of gynecomastia linked to specific classes of drugs.

The aim of this work was to review the scientific evidence on the risk of gynecomastia after administration of the drugs that are most frequently associated with the occurrence of this side effect.

\section{MAterials AND METHOdS}

Electronic databases (e.g., PubMed and EMBASE) were searched for articles published up to 30 June 2021. Five separate searches were performed using the following MESH terms: "spironolactone AND gynecomastia", "antiandrogens AND gynecomastia", "(finasteride OR dutasteride) AND gynecomastia", "psychotropic agents AND gynecomastia", "statins AND gynecomastia". Title and abstract and full-text screening were performed independently by two authors. We included randomized controlled trials (RCTs),

No conflict of interest declared. 
with an open-label or single/double blinded design, which enrolled patients treated for at least 6 weeks with antiandrogens, 5 alpha-reductase inhibitors, spironolactone, psychotropic drugs, and statins. Included studies should include a primary or secondary safety endpoint focusing on the side effects of treatment.

The following information was extracted from each study: author(s), publication year; study design; population; intervention; rate of gynecomastia (or breast enlargement or breast tenderness or pain or galacthorrea).

Two authors independently performed the quality assessment by identifying potential biases using the Cochrane risk of bias tool (2), focusing on the following items: random sequence generation, allocation concealment, blinding of participants and personnel, blinding of outcome assessors, incomplete outcomes, selective reporting and other biases. The risk of bias (ROB) was graded as high, low or unclear. Publication bias was assessed by visual inspection of funnel plots and by the Egger's regression test. Dichotomous data (presence/absence of gynecomastia) and number of per-protocol or intent-to-treat patients were extracted to calculate odds ratios (OR), confidence intervals (CI) to odds-ratios, and $\mathrm{Z}$ statistics according to the Mantel-Haenszel method. Meta-analysis was performed using a random-effects model. Heterogeneity was assessed by I2 statistics, reported with $95 \% \mathrm{CIs}$, and interpreted as of lesser importance $(\leq 40 \%)$, moderate $(30 \%-60 \%)$, substantial (50\%-90\%) or considerable ( $\geq 75 \%$ ), according to Cochrane criteria. The review (PROSPERO registration number: CRD42021276781) was conducted in accordance with PRISMA (Preferred Reporting Items for Systematic Reviews and Meta-Analyses) guidelines (3).

Statistical analysis was performed using the RevMan5 software. The Egger's test was performed using the MetaEssentials software (Rotterdam School of Management, Erasmus University, The Netherlands).

\section{RESULTS}

Database search for the association between gynecomastia and treatment with spironolactone, antiandrogens, alphareductase inhibitors, and antipsychotics retrieved 74, 215, 42 and 74 papers respectively. A total of 68 papers was screened by title/abstract. After full-text screening with removal of duplicates or of articles describing series reported in other reports we included 32 papers in this systematic review (4-35). Out of them 30 reports were included in the quantitative analysis (4-33).

A PRISMA flow-chart of the study selection process is shown in Figure 1. The supplementary appendix provides

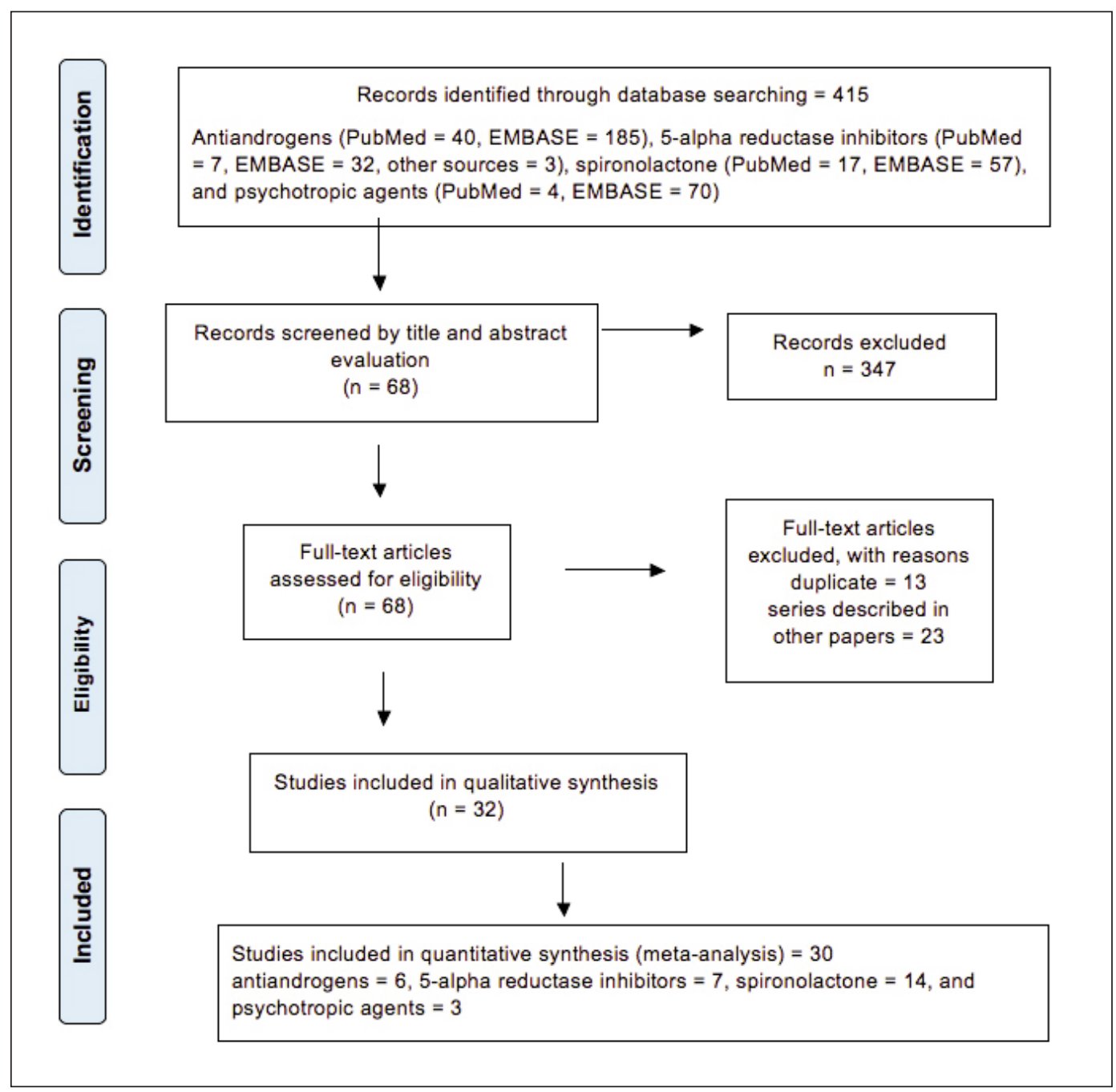

Figure 1. PRISMA flow chart summary of the study selection procedure. 
Table 1.

Drugs compared with placebo or active comparators - endpoint: gynecomastia.

Patient or population: various.

Settings: outpatient.

Intervention: antiandrogens, 5-alpha reductase inhibitors, spironolactone, risperidone, quetiapine.

Comparison: placebo or active comparator.

\begin{tabular}{|c|c|c|c|c|c|c|}
\hline \multirow[t]{3}{*}{ Comparisons } & \multicolumn{2}{|c|}{ Illustrative comparative risks (95\% Cl) } & \multirow{3}{*}{$\begin{array}{l}\text { Relative effect } \\
\qquad(95 \% \mathrm{CI})\end{array}$} & \multirow{3}{*}{$\begin{array}{c}\text { No of participants } \\
\text { (studies or comparisons) }\end{array}$} & \multirow{3}{*}{$\begin{array}{l}\text { Quality of the evidence } \\
\text { (GRADE) }\end{array}$} & \multirow[t]{3}{*}{ Comments } \\
\hline & $\begin{array}{l}\text { Assumed } \\
\text { control risk }\end{array}$ & $\begin{array}{l}\text { Corresponding } \\
\text { intervention risk }\end{array}$ & & & & \\
\hline & Placebo/active drug & Intervention & & & & \\
\hline Antiandrogens vs. placebo & 81.24 per 1000 & $\begin{array}{c}605.8 \text { per } 1000 \\
(498.91 \text { to } 703.40)\end{array}$ & $\begin{array}{c}\text { OR } 17.38 \\
(11.26 \text { to } 26.82)\end{array}$ & $\begin{array}{c}9599 \\
(6)\end{array}$ & $\begin{array}{l}\oplus \oplus \oplus \odot \\
\text { Moderate }\end{array}$ & $\begin{array}{l}\text { Reasons for upgrading: } \\
\text { - large magnitude of effect } \\
\text { Reasons for downgrading: } \\
\text { - indirectness of evidence } \\
\text { - risk of bias }\end{array}$ \\
\hline $\begin{array}{l}\text { 5-alpha reductase inhibitors } \\
\text { vs. placebo }\end{array}$ & 19.54 per 1000 & $\begin{array}{l}34.07 \text { per } 1000 \\
(29.59 \text { to } 39.44)\end{array}$ & $\begin{array}{c}\text { OR } 1.77 \\
(1.53 \text { to } 2.06)\end{array}$ & $\begin{array}{c}34860 \\
(7)\end{array}$ & $\begin{array}{c}\oplus \oplus \odot \odot \\
\text { LOW }\end{array}$ & $\begin{array}{l}\text { Reasons for upgrading: } \\
\text { none } \\
\text { Reasons for downgrading: } \\
\text { - risk of bias } \\
\text { - indirectness of evidence }\end{array}$ \\
\hline Spironolactone vs. placebo & 6.5 per 1000 & $\begin{array}{l}52.09 \text { per } 1000 \\
\text { (31.89 to } 83.94)\end{array}$ & $\begin{array}{c}\text { OR } 8.39 \\
\text { (5.03 to } 13.99)\end{array}$ & $\begin{array}{l}3745 \\
(14)\end{array}$ & $\begin{array}{l}\oplus \oplus \oplus \odot \\
\text { Moderate }\end{array}$ & $\begin{array}{l}\text { Reasons for upgrading: } \\
\text { - large magnitude of effect } \\
\text { Reasons for downgrading: } \\
\text { - risk of bias } \\
\text { - indirectness of evidence }\end{array}$ \\
\hline Risperidone vs. quetiapine & 19.35 per 1000 & $\begin{array}{c}78.56 \text { per } 1000 \\
(25.20 \text { to } 219.75)\end{array}$ & $\begin{array}{c}\text { OR } 4.32 \\
\text { (1.31 to } 14.27)\end{array}$ & $\begin{array}{l}343 \\
(3)\end{array}$ & $\begin{array}{l}\oplus \oplus \oplus \odot \\
\text { Moderate }\end{array}$ & $\begin{array}{l}\text { Reasons for upgrading: } \\
\text { - large magnitude of effect } \\
\text { Reasons for downgrading: } \\
\text { - imprecision (small sample size, wide 95\%Cl) } \\
\text { - risk of bias } \\
\text { - indirectness of evidence }\end{array}$ \\
\hline \multicolumn{7}{|c|}{$\begin{array}{l}\text { The corresponding intervention risk (and its 95\% confidence interval) is based on the assumed control risk in the comparison group and the relative effect of the intervention (and its } 95 \% \text { CI). It is calculated from the odds ratio using the formula: OR/[1-ACR x (1-OR)]. } \\
\text { Cl: Confidence Interval. OR: Odds Ratio. ACR: Assumed Control Risk. }\end{array}$} \\
\hline $\begin{array}{l}\text { GRADE Working Group grades of } \\
\text { High quality: Further research is } \\
\text { Moderate quality: Further researc } \\
\text { Low quality: Further research is } \\
\text { Very low quality: We are very unc }\end{array}$ & $\begin{array}{l}\text { vidence. } \\
\text { ery unlikely to change our confid } \\
\text { is likely to have an important in } \\
\text { ry likely to have an important im } \\
\text { rtain about the estimate. }\end{array}$ & $\begin{array}{l}\text { in the estimate of effect. } \\
\text { ton our confidence in the } \\
\text { on our confidence in the } e\end{array}$ & $\begin{array}{l}\text { te of effect and may ch } \\
\text { te of effect and is likely }\end{array}$ & $\begin{array}{l}\text { ge the estimate. } \\
\text { change the estimate. }\end{array}$ & 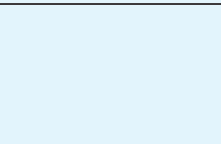 & \\
\hline
\end{tabular}

a list of included studies (Supplementary Materials), characteristics of the included trials and the risk-of-bias assessment.

We included the most recent paper reporting the cumulative results at 10-year follow-up of three studies of the administration of bicalutamide in the frame of the Early Prostate Cancer (EPC) program which includes three large, randomized trials conducted in the United States, Europe, Mexico and Australia (4).

Random-effects meta-analysis revealed that antiandrogen therapy is associated with significantly higher odds of gynecomastia (odds ratio, $\mathrm{OR}=17.38,95 \% \mathrm{CI}$ : 11.26 to 26.82; 6 trials, 9599 participants) compared with placebo $(4,5,7-9)$ or no treatment (6) (Figure 2A).

Similarly, alpha-5-reductase inhibitors ( $\mathrm{OR}=1.77,95 \%$ CI: 1.53 to 2.06; 6 trials, 34860 participants) and spironolactone (OR $=8.39,95 \%$ CI: 5.03 to $13.99 ; 14$ trials, 3745 participants) were significantly associated with gynecomastia (10-16) (Figures 2B-2C).

It is known that dutasteride can inhibit the activity of both type I and II reductases, whereas finasteride is not active on isoform II. This might suggest an increased risk of gynecomastia in patients taking dutasteride. However, the comparison between dutasteride and finasteride resulted in non-significantly different $(\mathrm{p}=0.31)$ odds of gynecomastia $(\mathrm{OR}=0.66,95 \% \mathrm{CI} 0.30-1.48 ; 2$ trials; 1697 participants) (Forest plot not shown). Risperidone was significantly $(p=0.02)$ associated with higher odds of gynecomastia compared to quetiapine $(\mathrm{OR}=4.32$, 95\% CI: 1.31 to $14.27 ; 3$ trials, 343 participants) (Figure 2D), but not olanzapine (Forest plot not shown).

Figure 3 shows the funnel plots for publication bias. No significant bias was identified by visual inspection and statistical analysis of funnel plots. Accordingly, the Egger's test (antiandrogens/placebo, $\mathrm{p}=0.43 ; 5$-alpha reductase inhibitors/placebo, $\mathrm{p}=0.37$; spironolattone/placebo, $\mathrm{p}=$ 0.53 ; risperidone/quetiapine, $\mathrm{p}=0.17$ ). Between-study heterogeneity was moderate for the antiandrogens vs. controls comparison ( $12=49 \%$ ), and of lesser importance for all other analyses.

Table 1 presents the summary of the findings of our pooled analyses, also including an evaluation of the quality of the evidence, performed according to GRADE criteria.

\section{Discussion}

Mechanisms regulating the growth of the breast tissue are complex and not fully elucidated $(36,37)$.

The breast tissue expresses receptors for both estrogens and androgens, which can induce the proliferation or inhibition of the growth and differentiation of the mammary gland, respectively. Gynecomastia can be caused either by overt reduction of circulating estrogen levels or 
Figure 2.

Pooled analysis of the comparisons between antiandrogens and placebo (panel A), 5-alpha-reductase inhibitors and placebo (panel B), spironolactone and placebo (panel C) and Risperidone and Quetiapine (panel D).

The diamonds show the position of the pooled odds-ratios, extending to the 95\% confidence interval limits.

Values to the right of the no-effect vertical axis show increased odds for gynecomastia.

$2 \mathrm{~A}$

\begin{tabular}{|c|c|c|c|c|c|c|c|c|c|c|}
\hline \multirow[b]{2}{*}{ Study or Subgroup } & \multicolumn{2}{|c|}{ Antiandrogens } & \multicolumn{2}{|c|}{ Placebo } & \multirow[b]{2}{*}{ Weight } & \multicolumn{2}{|l|}{ Odds Ratio } & \multirow{2}{*}{\multicolumn{2}{|c|}{$\begin{array}{c}\text { Odds Ratio } \\
\text { M-H, Random, } 95 \% \mathrm{Cl}\end{array}$}} & \\
\hline & Events & Total & Events & Total & & $\mathrm{M}-\mathrm{H}$, Random, $95 \% \mathrm{Cl}$ & & & & \\
\hline Alberts 2006 & 15 & 30 & 1 & 30 & $3.8 \%$ & $29.00[3.49,241.13]$ & & & & \\
\hline Berger 1995 & 83 & 370 & 4 & 93 & $12.8 \%$ & $6.43[2.29,18.04]$ & & & & \\
\hline Iversen 2010 & 2766 & 4052 & 334 & 4061 & $44.0 \%$ & $24.00[21.07,27.33]$ & & & - & a \\
\hline Narayan 1996 & 47 & 293 & 2 & 74 & $7.6 \%$ & $6.88[1.63,29.01]$ & & & & \\
\hline Shipley 2017 & 180 & 258 & 28 & 258 & $29.6 \%$ & $18.96[11.80,30.45]$ & & & $\rightarrow-$ & \\
\hline Zanardi 2009 & 18 & 54 & 0 & 26 & $2.2 \%$ & $26.86[1.55,465.89]$ & & & & \\
\hline Total $(95 \% \mathrm{Cl})$ & & 5057 & & 4542 & $100.0 \%$ & $17.38[11.26,26.82]$ & & & & \\
\hline Total events & 3109 & & 369 & & & & & & & \\
\hline $\begin{array}{l}\text { Heterogeneity: } \mathrm{Tau}^{2}= \\
\text { Test for overall effect: }\end{array}$ & $\begin{array}{l}0.11 ; \mathrm{Chi}^{2} \\
\mathrm{z}=12.89\end{array}$ & $\begin{array}{l}9.74, \mathrm{df} \\
<0.000\end{array}$ & $\begin{array}{l}=5(P= \\
01)\end{array}$ & $0.08) ; l^{\prime}$ & $=49 \%$ & & 0.01 & 0.1 Placebo $^{1}$ & $1 \frac{10}{\text { Antiandrogens }}$ & 100 \\
\hline
\end{tabular}

2B

\begin{tabular}{|c|c|c|c|c|c|c|c|c|c|c|}
\hline \multirow[b]{2}{*}{ Study or Subgroup } & \multicolumn{2}{|c|}{ 5alphareductase inhibitor } & \multicolumn{2}{|c|}{ Placebo } & \multirow[b]{2}{*}{ Weight } & \multirow{2}{*}{$\begin{array}{c}\text { Odds Ratio } \\
\mathrm{M}-\mathrm{H}, \text { Random, } 95 \% \mathrm{Cl}\end{array}$} & & \multirow{2}{*}{\multicolumn{2}{|c|}{$\begin{array}{c}\text { Odds Ratio } \\
\mathrm{M}-\mathrm{H}, \text { Random, } 95 \% \mathrm{Cl}\end{array}$}} & \\
\hline & Events & Total & Events & Total & & & & & & \\
\hline Amory 2007 & 3 & 33 & 2 & 32 & $0.6 \%$ & $1.50[0.23,9.63]$ & & & & \\
\hline Amory 2007b & 8 & 34 & 2 & 32 & $0.8 \%$ & $4.62[0.90,23.70]$ & & & & \\
\hline Andriole 2010 & 76 & 4105 & 43 & 4126 & $15.0 \%$ & $1.79[1.23,2.61]$ & & & $\varpi$ & \\
\hline McConnell 1998 & 27 & 1524 & 17 & 1516 & $5.9 \%$ & $1.59[0.86,2.93]$ & & & E & \\
\hline Na 2012 & 1 & 126 & 0 & 127 & $0.2 \%$ & $3.05[0.12,75.53]$ & & & & \\
\hline Roehrborn 2002 & 50 & 2167 & 16 & 2158 & $6.8 \%$ & $3.16[1.80,5.57]$ & & & & \\
\hline Thompson 2004 & 426 & 9423 & 261 & 9457 & $70.7 \%$ & $1.67[1.43,1.95]$ & & & $\square$ & \\
\hline Total $(95 \% \mathrm{CI})$ & & 17412 & & 17448 & $100.0 \%$ & $1.77[1.53,2.06]$ & & & $\boldsymbol{\theta}$ & \\
\hline Total events & 591 & & 341 & & & & & & & \\
\hline $\begin{array}{l}\text { Heterogeneity: } \mathrm{Tau}^{2}= \\
\text { Test for overall effect }\end{array}$ & $\begin{array}{l}0.00 ; \mathrm{Chi}^{2}=6.16 \\
Z=7.51(P<0.0\end{array}$ & $(P=0.4$ & (1); $;\left.\right|^{2}=3 \%$ & & & & 0.01 & 0.1 & 10 & 100 \\
\hline
\end{tabular}

\section{$2 \mathrm{C}$}

\begin{tabular}{|c|c|c|c|c|c|c|c|c|c|}
\hline \multirow{2}{*}{ Study or Subgroup } & \multicolumn{2}{|c|}{ Spironolactone } & \multicolumn{2}{|c|}{ Placebo } & \multirow{2}{*}{ Weight } & \multirow{2}{*}{$\begin{array}{c}\text { Odds Ratio } \\
\text { M-H, Random, } 95 \% \mathrm{Cl}\end{array}$} & \multirow{2}{*}{\multicolumn{3}{|c|}{$\begin{array}{c}\text { Odds Ratio } \\
\text { M-H, Random, } 95 \% \mathrm{Cl}\end{array}$}} \\
\hline & Events & Total & Events & Total & & & & & \\
\hline Bianchi 2006 & 6 & 83 & 0 & 82 & $3.1 \%$ & $13.84[0.77,249.78]$ & & & \\
\hline Charytan 2019 & 3 & 76 & 2 & 51 & $7.8 \%$ & $1.01[0.16,6.25]$ & & & \\
\hline Edelmann 2013 & 9 & 213 & 0 & 209 & $3.2 \%$ & $19.46[1.13,336.61]$ & & & \\
\hline Gao 2007 & 3 & 58 & 0 & 58 & $2.9 \%$ & $7.38[0.37,146.12]$ & & & \\
\hline Ito 2014 & 11 & 78 & 2 & 80 & $11.0 \%$ & $6.40[1.37,29.92]$ & & & \\
\hline Kayrak 2010 & 3 & 55 & 0 & 55 & $2.9 \%$ & $7.40[0.37,146.73]$ & & & \\
\hline Matsumoto 2014 & 16 & 157 & 0 & 152 & $3.3 \%$ & $35.57[2.11,598.33]$ & & & \\
\hline Ni 2014 & 1 & 40 & 0 & 36 & $2.5 \%$ & $2.77[0.11,70.23]$ & & & \\
\hline Pitt 1999 & 82 & 821 & 8 & 841 & $48.7 \%$ & $11.55[5.55,24.04]$ & & & $\rightarrow-$ \\
\hline Skvortsov 2013 & 5 & 19 & 0 & 30 & $3.0 \%$ & $23.14[1.20,447.32]$ & & & \\
\hline Tofte 2020 & 3 & 102 & 0 & 107 & $3.0 \%$ & $7.56[0.39,148.26]$ & & & \\
\hline Vatankulu 2013 & 4 & 104 & 0 & 56 & $3.0 \%$ & $5.06[0.27,95.70]$ & & & \\
\hline Vizzardi 2015 & 1 & 51 & 0 & 51 & $2.5 \%$ & $3.06[0.12,76.88]$ & & & \\
\hline Zarraga 2012 & 4 & 44 & 0 & 36 & $3.0 \%$ & $8.11[0.42,155.87]$ & & & \\
\hline Total $(95 \% \mathrm{Cl})$ & & 1901 & & 1844 & $100.0 \%$ & $8.39[5.03,13.99]$ & & & \\
\hline Total events & 151 & & 12 & & & & & & \\
\hline $\begin{array}{l}\text { Heterogeneity: } \mathrm{Tau}^{2}= \\
\text { Test for overall effect: }\end{array}$ & $\begin{array}{l}.00 ; \mathrm{Chi}^{2}= \\
\mathrm{Z}=8.15(\mathrm{P}\end{array}$ & $\begin{array}{l}11, \mathrm{df} \\
0.0000\end{array}$ & $\begin{array}{l}=13(P= \\
\text { 1) }\end{array}$ & $0.76) ;$ & $I^{2}=0 \%$ & & 0.002 & $\begin{array}{l}0.1 \\
\text { Placebo }\end{array}$ & $\begin{array}{lc}1 & 10 \\
\end{array}$ \\
\hline
\end{tabular}

2D

\begin{tabular}{|c|c|c|c|c|c|c|c|c|c|c|}
\hline \multirow[b]{2}{*}{ Study or Subgroup } & \multicolumn{2}{|c|}{ Risperidone } & \multicolumn{2}{|c|}{ Quetiapine } & \multirow[b]{2}{*}{ Weight } & \multirow{2}{*}{$\begin{array}{c}\text { Odds Ratio } \\
\mathrm{M}-\mathrm{H} \text {, Random, } 95 \% \mathrm{Cl}\end{array}$} & & \multirow{2}{*}{\multicolumn{2}{|c|}{$\begin{array}{l}\text { Odds Ratio } \\
\mathrm{M}-\mathrm{H}, \text { Random, } 95 \% \mathrm{Cl} \\
\end{array}$}} & \\
\hline & Events & Total & Events & Total & & & & & & \\
\hline Kelly 2006 & 1 & 9 & 0 & 6 & $12.7 \%$ & $2.29[0.08,66.02]$ & & & & \\
\hline McEvoy 2006 & 0 & 16 & 0 & 15 & & Not estimable & & & & \\
\hline McEvoy 2007 & 13 & 133 & 3 & 134 & $87.3 \%$ & $4.73[1.32,17.01]$ & & & & \\
\hline Total $(95 \% \mathrm{Cl})$ & & 158 & & 155 & $100.0 \%$ & $4.32[1.31,14.27]$ & & & & \\
\hline Total events & 14 & & 3 & & & & & & & \\
\hline $\begin{array}{l}\text { Heterogeneity: } \mathrm{Tau}^{2}= \\
\text { Test for overall effect: }\end{array}$ & $\begin{array}{l}0.00 ; \mathrm{Chi}^{2} \\
\mathrm{Z}=2.40(\mathrm{~F}\end{array}$ & $\begin{array}{l}=0.16, \\
=0.02\end{array}$ & $f=1(P=$ & 0.69); & $I^{2}=0 \%$ & & 0.01 & $\begin{array}{c}0.1 \\
\text { Quetiapine }\end{array}$ & $\begin{array}{lr}1 & 10 \\
& \text { Risperidone }\end{array}$ & 100 \\
\hline
\end{tabular}


Figure 3.

Funnel plots for publication bias analysis. Top-left, antiandrogens vs. placebo; top-right, 5-alpha-reductase inhibitors vs. placebo; bottom-left, spironolactone vs. placebo; bottom-right, risperidone vs. quetiapine.

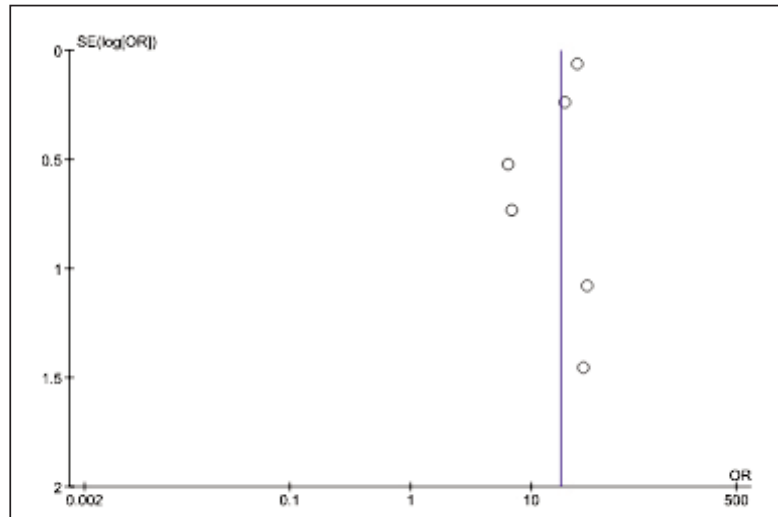

ANTIANDROGENS/PLACEBO

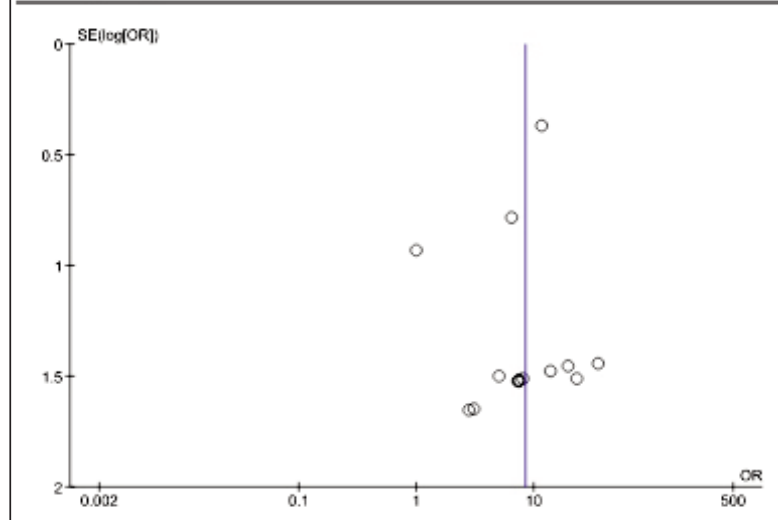

SPIRONOLACTONE/PLACEBO

by an increase of androgen serum levels. In addition, imbalances between estrogen and androgen levels, which may retain serum concentrations within the normal ranges, may cause such effects. Furthermore, activity of estrogens and androgens can be locally modulated in the breast tissue (i) by increased local production of estrogens or decreased inactivation of estrogens, (ii) by decreased local production of androgens, or (iii) by changes in the number and/or activity of androgen or estrogen receptors. Besides androgens and estrogens, other hormones can interfere with the growth of men's breast tissue, which presents receptors for prolactin, progesterone, insulin-like growth factor (IGF)-1, IGF-2, luteinizing hormone (LH) and/or human chorionic gonadotropin (hCG). Our metaanalysis confirmed that antiandrogens are associated with the highest risk of gynecomastia.

Antiandrogens are used for the treatment of prostate cancer as monotherapy or in combination with LHRH inhibitors. Bicalutamide is the most used antiandrogen, though other agents, either steroidal like cyproterone acetate or non-steroidal like flutamide, have also been used for the treatment of prostate cancer. These agents bind to androgen receptors competitively, thus inhibiting testosterone or dihydrotestosterone receptor binding and activity. The administration of non-steroidal antiandrogens, as bicalutamide, causes an increase in the synthesis of testos-

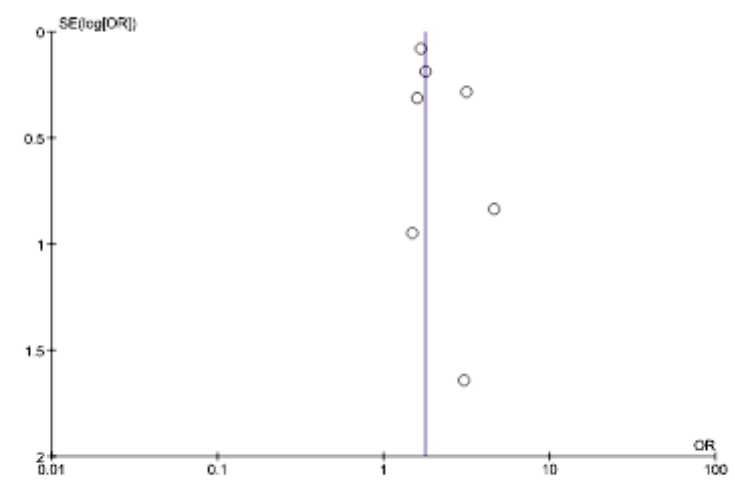

5-ALPHA-REDUCTASE INHIBITORS/PLACEBO

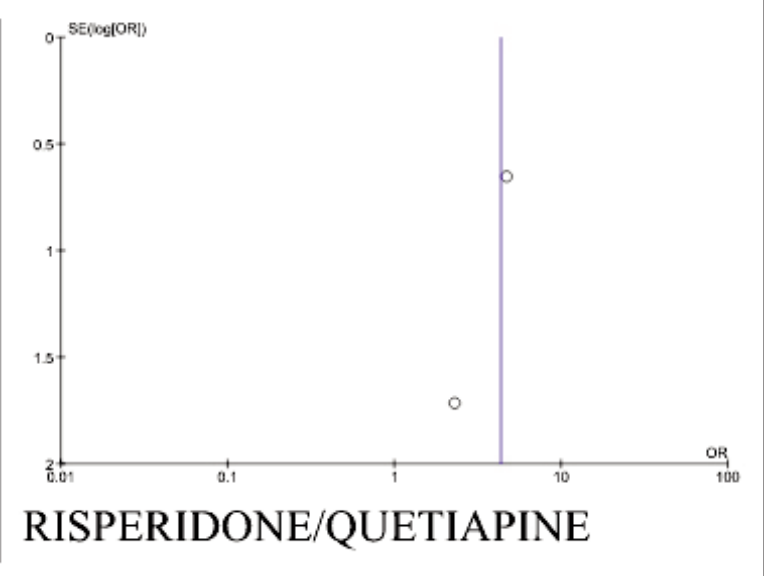

terone due to the inhibition of the negative feedback of the hypothalamic-pituitary-gonadal axis. Increased availability of testosterone causes an increase in estradiol levels due to aromatization of testosterone. These hormonal changes explain the high risk of gynecomastia, which tends to occur in the first year of administration. The evaluation at different time intervals of the rates of gynecomastia in patients taking bicalutamide included in the same series of Early Prostate Cancer program showed rates of gynecomastia and breast pain of $64.9 \%$ and $65.1 \%$ after a median follow up of 2.6 years (38), $66.3 \%$ and $67.9 \%$ at 5.1 years (39) and 66.8 and $73.7 \%$ at 9.7 years (40). Cyproterone acetate is expected to involve a lower risk of gynecomastia because, in contrast to nonsteroidal antiandrogens, it can decrease estrogen levels via inhibition of the secretion of gonadotropins. However, a comparative study by EORTC described similar gynecomastia rates in patients treated with cyproterone or flutamide, though the latter was more frequently associated with painful gynecomastia (35).

Inhibitors of 5-alpha-reductase are widely used for the treatment of benign prostatic hyperplasia. These agents inhibit the conversion of testosterone to dihydrotestosterone through inhibition of the 5-alpha-reductase enzyme, thus reducing prostate cell proliferation. They also cause an increase in the synthesis of testosterone and, consequently, of estrogen through aromatization of 
testosterone. Spironolactone may induce gynecomastia by several mechanisms: (i) increased peripheral conversion of testosterone to estradiol, (ii) displacement of testosterone from SHBG, or (iii) binding to peripheral androgen receptors to competitively inhibit testosterone and dihydrotestosterone. Our meta-analysis confirms that spironolactone and 5-alpha-reductase inhibitors are associated with an increased risk of gynecomastia, although to a lesser extent than antiandrogens.

Although an increased risk of gynecomastia could be expected in patients taking dutasteride, which inhibits the activity of both type 1 and 2 reductases, our metaanalysis could not demonstrate a different risk of gynecomastia between finasteride and dutasteride (16).

Statins are inhibitors of the 3-hydroxy-3-methylglutaryl coenzyme A (HMG-CoA) reductase, an enzyme that lowers the serum levels of lipids by blocking the pathways of cholesterol synthesis. Inhibition of adrenal and gonadal steroid synthesis may entail to an increased estradiol: testosterone ratio. A meta-analysis showed that a reduction in circulating testosterone levels in patients receiving statin (41). Our search did not retrieve randomized controlled studies that evaluated the possible occurrence of gynecomastia after treatment with statins. It was therefore not possible to investigate the potential risk of gynecomastia associated with the use of these drugs, which was observed following treatment with statins in a case-control cohort study (42). On the other hand, some case reports have suggested that pravastatin, atorvastatin, and rosuvastatin may cause gynecomastia that can be reverted by withdrawal or substitution with a less potent statin. In addition, pharmacovigilance studies include HMG-CoA reductase inhibitors among the most frequent causes of drug-induced gynecomastia $(43,44)$.

Some antipsychotics are correlated with the risk of gynecomastia because of their effect on prolactin secretion. Antipsychotics block pituitary dopamine D2 receptors and prevent their inhibitory effect on prolactin secretion. Hyperprolactinemia may in turn decrease the secretion of GnRH by hypothalamus feedback causing hypogonadism. Nonetheless, prolactin receptors have also been found in male breast tissue, and this may also contribute to the development of gynecomastia $(45,46)$.

Most first-generation antipsychotics and some secondgeneration antipsychotics, particularly risperidone and paliperidone, have been found to increase prolactin levels, with accompanying gynecomastia.

The onset of gynecomastia after administration of risperidone is more frequently associated with the use of high doses of the drug and can be triggered by the simultaneous administration of fluoxetine which can interfere in the metabolism of risperidone by inhibition of cytochrome P450. Our meta-analysis confirmed a greater risk of gynecomastia associated with the use of risperidone compared to another atypical antipsychotics. limitation of the meta-analysis evidence presented in this review is the possible under-reporting of breast enlargement or gynecomastia in the female population taking spironolactone or antipsychotics because this effect may be unnoticed or even considered a beneficial effect by female patients, while in the male population it may have been reported with more attention, as it modifies the body image more heavily. Unfortunately, no study has provided a separate assessment of the appearance of this side effect in relation to gender. In populations of adult women who took spironolactone for the treatment of acne, the appearance of breast tenderness and breast enlargement was estimated at $2.5 \%$ and $2.1 \%$ respectively $(47,48)$. The prevalence of gynecomastia could therefore be underestimated in mixed gender populations taking spironolactone or antipsychotics compared to male populations receiving antiandrogens or alpha-reductase inhibitors.

In conclusion, our study confirmed the high risk of gynecomastia in patients taking antiandrogens for the treatment of prostate cancer. The frequent occurrence of gynecomastia is a limiting factor of this treatment and ablation of the breast tissue by ionizing radiation is sometimes used to prevent this effect. The risk of gynecomastia is lower but significantly higher than placebo in patients receiving spironolactone, 5-alpha-reductase inhibitors, and atypical antipsychotics (risperidone vs. quetiapine). The potential risk of gynecomastia associated with the use of statins should be better assessed with studies evaluating the long-term side effects of these drugs. In the clinical practice, the possible additive or synergic interaction of several drugs predisposing to the onset of gynecomastia must be cautiously considered.

\section{References}

1. Bowman JD, Hyunah Kim H, Bustamante JJ. Drug-induced gynecomastia. Pharmacotherapy. 2012; 32:1123-1140

2. Higgins JP, Altman DG, Gøtzsche P, Cet al.Cochrane Bias Methods Group; Cochrane Statistical Methods Group. The Cochrane Collaboration's tool for assessing risk of bias in randomised trials. BMJ. 2011; 343:d5928.

3. Moher D, Liberati A, Tetzlaff J, Altman DG. The PRISMA Group (2009) Preferred Reporting Items for Systematic Reviews and MetaAnalyses: The PRISMA Statement. PLoS Med 6: e1000097.

4. Iversen P, McLeod DG, See WA, et al. Casodex Early Prostate Cancer Trialists' Group. Antiandrogen monotherapy in patients with localized or locally advanced prostate cancer: final results from the bicalutamide Early Prostate Cancer programme at a median followup of 9.7 years. BJU Int. 2010; 105:1074-81.

5. Shipley WU, Seiferheld W, Lukka HR, et al. NRG Oncology RTOG. Radiation with or without Antiandrogen Therapy in Recurrent Prostate Cancer. N Engl J Med. 2017; 376:417-428.

6. Zanardi S, Puntoni M, Maffezzini M, et al. Phase I-II trial of weekly bicalutamide in men with elevated prostate-specific antigen and negative prostate biopsies. Cancer Prev Res (Phila). 2009; 2:377-84.

7. Alberts SR, Novotny PJ, Sloan JA, et al. Flutamide in men with prostatic intraepithelial neoplasia: A randomized, placebo-controlled chemoprevention trial American Journal of Therapeutics. 2006; 13:4(291-297).

8. Narayan P, Trachtenberg J, Lepor H, et al. A dose-response study of the effect of flutamide on benign prostatic hyperplasia: results of a multicenter study. Urology. 1996; 47:497-504.

9. Berger BM, Naadimuthu A, Boddy A, et al. The effect of zanoterone, a steroidal androgen receptor antagonist, in men with benign prostatic hyperplasia. The Zanoterone Study Group. J Urol. 1995; 154:1060-4. 
10. Andriole GL, Bostwick DG, Brawley OW, et al. REDUCE Study Group Effect of dutasteride on the risk of prostate cancer. N Engl J Med. 2010; 362:1192-202

11. Na Y, Ye Z, Zhang S. Efficacy and Safety of Dutasteride in Chinese Adults with Symptomatic Benign Prostatic Hyperplasia: A Randomized, Double-Blind, Parallel-Group, Placebo-Controlled Study with an Open-Label Extension. Clin Drug Investig. 2012; 32:29-39.

12. Roehrborn CG, Boyle P, Nickel J, et al. Efficacy and safety of a dual inhibitor of 5-alpha-reductase types 1 and 2 (dutasteride) in men with benign prostatic hyperplasia Urology. 2002; 60:3(434-441).

13. McConnell JD, Bruskewitz R, Walsh P, et al. The effect of finasteride on the risk of acute urinary retention and the need for surgical treatment among men with benign prostatic hyperplasia. Finasteride Long-Term Efficacy and Safety Study Group. N Engl J Med. 1998; 338:557-63.

14. Thompson IM, Goodman PJ, Tangen CM, et al. The influence of finasteride on the development of prostate cancer.N Engl J Med. 2003; 349:215-24.

15. Amory JK, Wang C, Swerdloff RS, et al. The effect of $5 \alpha$-reductase inhibition with dutasteride and finasteride on semen parameters and serum hormones in healthy men Journal of Clinical Endocrinology and Metabolism. 2007; 92:5(1659-1665).

16. Nickel JC, Gilling P, Tammela TL, et al. Comparison of dutasteride and finasteride for treating benign prostatic hyperplasia: the Enlarged Prostate International Comparator Study (EPICS). BJU Int. 2011; 108:388-94.

17. Bianchi S, Bigazzi R, Campese VM. Long-term effects of spironolactone on proteinuria and kidney function in patients with chronic kidney disease Kidney International 2006; 70:2116-2123.

18. Charytan DM, Himmelfarb J, Ikizler TA, et al. Hemodialysis Novel Therapies Consortium. Safety and cardiovascular efficacy of spironolactone in dialysis-dependent ESRD (SPin-D): a randomized, placebocontrolled, multiple dosage trial. Kidney Int. 2019; 95:973-982.

19. Edelmann F, Wachter R, Schmidt AG, et al. Effect of spironolactone on diastolic function and exercise capacity in patients with heart failure with preserved ejection fraction: The Aldo-DHF randomized controlled trial JAMA - Journal of the American Medical Association 2013; 309:781-791.

20. Gao X, Peng L, Adhikari CM, et al. Spironolactone Reduced Arrhythmia and Maintained Magnesium Homeostasis in Patients With Congestive Heart Failure Journal of Cardiac Failure 2007; 13:170-177.

21. Ito $Y$, Mizuno M, Suzuki Y, et al. Long-term effects of spironolactone in peritoneal dialysis patients Journal of the American Society of Nephrology. 2014; 25:1094-1102.

22. Kayrak M, Bacaksiz A, Vatankulu MA, et al. The effects of spironolactone on atrial remodeling in patients with preserved left ventricular function after an acute myocardial infarction: A randomized follow-up study Coronary Artery Disease. 2010; 21:477-485.

23. Matsumoto Y, Mori Y, Kageyama S, et al. Spironolactone reduces cardiovascular and cerebrovascular morbidity and mortality in hemodialysis patients. J Am Coll Cardiol. 2014; 63:528-36.

24. Ni X, Zhang J, Zhang P, et al. Effects of spironolactone on dialysis patients with refractory hypertension: A randomized controlled study Journal of Clinical Hypertension. 2014; 16:658-663.

25. Pitt B, Zannad F, Remme WJ, et al. The effect of spironolactone on morbidity and mortality in patients with severe heart failure. Randomized Aldactone Evaluation Study Investigators. N Engl J Med. 1999; 341:709-17.
26. Skvortsov AA, Mareev VY, Chelmakina SM, et al. Efficacy and safety of long-term application of spironolactone in patients with moderate and severe chronic heart failure receiving optimal therapy. Kardiologiia. 2007; 47:12-23.

27. Tofte N, Lindhardt M, Adamova K, et al. PRIORITY investigators. Early detection of diabetic kidney disease by urinary proteomics and subsequent intervention with spironolactone to delay progression (PRIORITY): a prospective observational study and embedded randomised placebo-controlled trial. Lancet Diabetes Endocrinol. 2020; 8:301-312.

28. Vatankulu MA, Bacaksiz A, Sonmez O, et al. Does spironolactone have a dose-dependent effect on left ventricular remodeling in patients with preserved left ventricular function after an acute myocardial infarction? Cardiovascular Therapeutics. 2013; 31:224-229.

29. Vizzardi E, Pina PD, Caretta G, et al. The effect of aldosteroneantagonist therapy on aortic elastic properties in patients with nonischemic dilated cardiomyopathy Journal of Cardiovascular Medicine. 2015; 16:597-602.

30. Zarraga IGE, Dougherty CM, MacMurdy KS, Raitt MH. Tachyarrhythmias the effect of spironolactone on ventricular tachyarrhythmias in patients with implantable cardioverter-defibrillators Circulation: Arrhythmia and Electrophysiology. 2012; 5:739-747.

31. Kelly DL., Conley RR. A randomized double-blind 12-week study of quetiapine, risperidone or fluphenazine on sexual functioning in people with schizophrenia Psychoneuroendocrinology. 2006; 31:340346

32. McEvoy JP, Lieberman JA, Stroup TS, et al. CATIE Investigators. Effectiveness of clozapine versus olanzapine, quetiapine, and risperidone in patients with chronic schizophrenia who did not respond to prior atypical antipsychotic treatment. Am J Psychiatry. 2006; 163:600-10.

33. McEvoy JP, Lieberman JA, Perkins DO, et al. Efficacy and tolerability of olanzapine, quetiapine, and risperidone in the treatment of early psychosis: A randomized, double-blind 52-week comparison American Journal of Psychiatry. 2007; 164:1050-1060.

34. McEvoy JP, Byerly M, Hamer RM, et al. Effectiveness of paliperidone palmitate vs haloperidol decanoate for maintenance treatment of schizophrenia: a randomized clinical trial. JAMA. 2014; 311:1978-87.

35. Schröder FH, Whelan P, de Reijke TM, et al. Members of the EORTC Genito-Urinary Group. Metastatic prostate cancer treated by flutamide versus cyproterone acetate. Final analysis of the "European Organization for Research and Treatment of Cancer" (EORTC) Protocol 30892. Eur Urol. 2004; 45:457-64.

36. Narula HS, Carlson HE. Gynaecomastia-pathophysiology, diagnosis and treatment. Nat Rev Endocrinol. 2014; 10:684-698.

37. Kanakis GA, Nordkap L, Bang AK, et al. EAA clinical practice guidelines-gynecomastia evaluation and management. Andrology. 2019; 7:778-793.

38. Wirth M, Tyrrell C, Wallace M, et al. Bicalutamide (Casodex) $150 \mathrm{mg}$ as immediate therapy in patients with localized or locally advanced prostate cancer significantly reduces the risk of disease progression Urology. 2001; 58:146-150.

39. Wirth M, Tyrrell C, Delaere K, et al. Bicalutamide ('Casodex') $150 \mathrm{mg}$ in addition to standard care in patients with nonmetastatic prostate cancer: Updated results from a randomised double-blind phase III study (median follow-up 5.1y) in the early prostate cancer programme Prostate Cancer and Prostatic Diseases 2005; 8:194200.

40. Iversen P, McLeod DG, See WA, et al. Casodex Early Prostate 
Cancer Trialists' Group. Antiandrogen monotherapy in patients with localized or locally advanced prostate cancer: final results from the bicalutamide Early Prostate Cancer programme at a median followup of 9.7 years. BJU Int. 2010; 105:1074-81.

41. Skeldon SC, Carleton B, Brophy JM, et al. Statin medications and the risk of gynecomastia. Clin Endocrinol (Oxf). 2018; 89:470-473.

42. Schooling CM, Au Yeung SL, Freeman G, Cowling BJ. The effect of statins on testosterone in men and women, a systematic review and meta-analysis of randomized controlled trials. BMC Med. 2013; 11:57.

43. Roberto G, Biagi C, Montanaro N, et al. Statin-associated gynecomastia: evidence coming from the Italian spontaneous $A D R$ reporting database and literature. Eur J Clin Pharmacol. 2012; 68:1007-11.

44. Batteux B, Llopis B, Muller C, et al. French National Network of Pharmacovigilance Centres. The drugs that mostly frequently induce gynecomastia: A national case - noncase study. Therapie. 2020; 75:225-238.

45. Grigg J, Worsley R, Thew C, et al. Antipsychotic-induced hyperprolactinemia: synthesis of world-wide guidelines and integrated recommendations for assessment, management and future research. Psychopharmacology. 2017; 234:3279-3297.

46. Ferreira M, Mesquita M, Quaresma M \& André S. Prolactin receptor expression in gynaecomastia and male breast carcinoma. Histopathology. 2008; 53:56-61.

47. Layton AM, Eady EA, Whitehouse H, et al. Oral Spironolactone for Acne Vulgaris in Adult Females: A Hybrid Systematic Review. Am J Clin Dermatol. 2017; 18:169-191.

48. Muhlemann MF, Carter GD, Cream JJ, Wise P. Oral spironolactone: an effective treatment for acne vulgaris in women. $\mathrm{Br} \mathrm{J}$ Dermatol. 1986; 115:227-32.

\section{Correspondence}

Alberto Trinchieri, MD (Corresponding Author)

alberto.trinchieri@gmail.com

School of Urology, University of Milan

Via Commenda 15, 20100 Milano (Italy)

Gianpaolo Perletti, PhD

gianpaolo.perletti@uninsubria.it

Department of Biotechnology and Life Sciences, Section of Medical

and Surgical Sciences, University of Insubria, Varese (Italy)

Vittorio Magri, MD

vittorio.magri@yahoo.it

Urology Secondary Care Clinic, ASST-Nord, Milan (Italy)

Konstantinos Stamatiou, MD

stamatiouk@gmail.com

Department of Urology, Tzaneio Hospital, Pireus (Greece)

Margherita Trinchieri, MD

margherita.trinchieri11@gmail.com

Department of Neuroscience, Psychiatric Unit, University of Parma, Parma (Italy)

Emanuele Montanari, MD

emanuele.montanari@unimi.it

Department of Urology, IRCCS Ca' Granda Ospedale Maggiore Policlinico -

University of Milan, Milan (Italy) 